\title{
LA FISIOLOGÍA DEL AMOR
}

\author{
EL DIÁLOGO DE FRANCESCO PATRIZI SOBRE LOS BESOS
}

THE PHYSIOLOGY OF LOVE

Francesco Patrizi's dialogue on kissing

A FISIOLOGIA DO AMOR

O diálogo de Francesco Patrizi sobre o beijo

\author{
Susana Gómez López \\ (Universidad Complutense de Madrid) \\ susanagl@filos.ucm.es
}

Recibido: $18 / 10 / 2021$

Aprobado: 20/12/2021

\begin{abstract}
RESUMEN
El amor siempre ha sido objeto de reflexión de filósofos, tema privilegiado de poetas, artistas y moralistas de toda índole e inclinación. Desde el siglo XVII, la propia historia del cuerpo, de la concepción de las pasiones y las emociones ha ido "descarnando" el amor, separándolo de los procesos corporales, fisiológicos. Antes de llegar a aquel momento crítico de la historia de la cultura europea, hubo ciertamente quienes defendieron un amor separado del cuerpo, pero lejos de resultar algo obvio, tuvieron que defender sus argumentos ante una profunda tradición científica y filosófica que consideraba el amor una patología inseparable de los procesos fisiológicos. En este artículo se hace un repaso por el concepto de hereos, aegritudo amoris, para presentar un texto de Francesco Patrizi da Cherso (1529-1597), Il Delfino, overo del bacio, que constituye una de las más claras exposiciones de una concepción fisiológica del amor, una naturalización del amor que sorprende y resulta especialmente interesante por su síntesis con la tradición platónica.
\end{abstract}

Palabras clave: amor. hereos. aegritudo amoris. enfermedad de amor. Patrizi da Cherso.

\section{ABSTRACT}

Love has always been an issue for philosophers, a privileged topic for poets, artists and moralists of all sorts and inclinations. Since the seventtenth century, the history of the body, of the conception of passions and emotions, has "disembodied" love, separating it from physiological processes. Before reaching that critical moment in the history of European culture, there were certainly advocates of a love divorced from the body, however, far from being obvious, they had to defend their arguments against a deeply rooted scientific and philosophical tradition that considered love a pathology inseparable from physiological processes. This article reviews the concept of hereos, aegritudo amoris, in order to introduce a text by Francesco Patrizi da Cherso (1529-1597), Il Delfino, overo del bacio, which is one of the clearest expressions of a physiological conception of love, a true naturalization of love both surprising and particularly interesting for its synthesis with the Platonic tradition. 
Keywords: love. hereos. aegritudo amoris. Lovesickness. Patrizi da Cherso.

\section{RESUMO}

O amor sempre foi um objeto de reflexão para filósofos, um assunto privilegiado para poetas, artistas e moralistas de todos os tipos e inclinações. Desde o século XVII, a própria história do corpo, da concepção das paixões e das emoções, tem sido "despojada" do amor, separando-o dos processos corporais e fisiológicos. Antes de chegar àquele momento crítico na história da cultura européia, certamente havia quem defendesse um amor separado do corpo, mas longe de ser óbvio, eles tinham que defender seus argumentos contra uma profunda tradição científica e filosófica que considerava o amor uma patologia inseparável de processos fisiológicos. Este artigo revisa o conceito do hereos, aegritudo amoris, para apresentar um texto de Francesco Patrizi da Cherso (1529-1597), Il Delfino, overo del bacio, que constitui uma das mais claras exposições de uma concepção fisiológica do amor, uma naturalização do amor surpreendente e particularmente interessante para sua síntese com a tradição platônica.

Palavras-chave: amor. hereos. aegritudo amoris. doença do amor. Patrizi da Cherso.

\section{Introducción}

Otra razón se opone con toda evidencia al amor: a causa del amor y de las obras de Venus el cuerpo humano se debilita y con ello los hombres pierden sus fuerzas en el combate. Tres son las causas, bastante razonables, de que ocurra así: en primer lugar, porque, según demuestra la ciencia médica, la energía del cuerpo se debilita mucho con las prácticas de Venus, en segundo, porque el amor hace que el cuerpo coma y beba menos, con lo que, con toda razón, su energía disminuye. Y por último, porque el amor aleja el sueño y suele privar al hombre de todo descanso. La privación del sueño produce una mala digestión y una gran debilidad física [...] Puede aducirse una cuarta razón de por qué el cuerpo humano se debilita: creemos que a causa del pecado todos los dones divinos disminuyen en el hombre y se acorta el tiempo de vida.

Así escribía Andrés el Capellán (1150-c. 1220) en el Libro III de su De amore (57-59 [389]), dedicado fundamentalmente a exponer toda una serie de razones por las que el hombre haría bien en alejarse de la pasión amorosa y, si fuese posible, no caer siquiera en ella. Los motivos de orden teológico estaban muy presentes en su condena del arte amatoria: el amor es pecaminoso y la divinidad utiliza el cuerpo, los instrumentos de la fisiología, para castigar al hombre. La cuestión de las causas y efectos somáticos del amor está presente en casi todos los textos de la tradición literaria, médica y filosófica sobre el amor, sin embargo, en cada obra, cada autor, adquiere matices y significados diferentes, a veces incluso diametralmente opuestos. No basta en absoluto insertar tales comentarios e interpretaciones médicofilosóficas en el marco de una dicotomía entre platónicos o aristotélicos, entre discursos sobre el amor cortesano o sobre el amor metafísico, por citar solo algunas de las categorías más frecuentemente usadas al abordar la historia de la tradición literaria sobre el amor. El De amore de Andrés el Capellán es un claro ejemplo de una particular síntesis de concepciones médicas heredadas de la antigüedad, de una corriente de literatura cortesana que florecía en su época y de unas profundas convicciones teológicas. ${ }^{1}$ Hubo y habrá, antes y después de la obra de Andrés el Capellán, textos de amor cortesano exentos de motivaciones teológicas, o textos sobre la medicina del amor indiferentes a los temas cortesanos.

Cuando Andrés el Capellán escribía, en el Occidente latino las teorías médicas del amor apenas habían empezado a tener eco. Dando un salto en la historia, quiero presentar aquí un texto poco conocido redactado a mediados del siglo XVI: Il Delfino, overo del bacio, de Francesco Patrizi da Cherso. En el espacio de aquellos cuatro siglos que median entre el De amore del Capellán y el Delfino, la filosofía de Aristóteles se había impuesto y había comenzado a derrumbarse, la medicina galénica se había consolidado como modelo del funcionamiento del cuerpo humano, de su estructura, sus enfermedades y sus correspondientes terapias. Los médicos de Salerno, Bolonia, Padua o Montpellier habían

\footnotetext{
${ }^{1}$ Véase Martínez (2015).
} 
enriquecido, comentado y a veces debatido las ideas de Galeno. Las obras de Avicena, el príncipe de los médicos, se habían convertido en la referencia fundamental para todo aquel que desease profundizar en los secretos del cuerpo humano y de los males que lo aquejaban. Platón había renacido en las calles y cortes florentinas casi al mismo tiempo que se fundía con las corrientes herméticas. El texto de Patrizi, como veremos más adelante, bebe de todas esas tradiciones y en él hay ecos de la literatura cortesana del amor, de la filosofía neoplatónica, de la fisiología aristotélica y de esa poesía del dolce stil nuovo a la que Dante, siendo él también uno de los stilnovisti, había criticado con dureza por su interés en el amor profano, carnal o sensual.

\section{Poesía, amor y medicina}

Corrían los últimos años del siglo XI cuando las cortes francesas empezaron a disfrutar de un arte tan placentero, jocoso y picante como emotivo e inspirador. Eran los versos recitados por los nuevos trovadores del amor cortesano, que poco tardaron en traspasar fronteras y extenderse por toda Europa. Algún tiempo después, en la Sicilia del siglo XIII, floreció en la corte de Federico II una corriente de poesía amorosa, uno de cuyos más notables exponentes fue Giacomo da Lentini (1210-1260), que en uno de sus sonetos escribía:

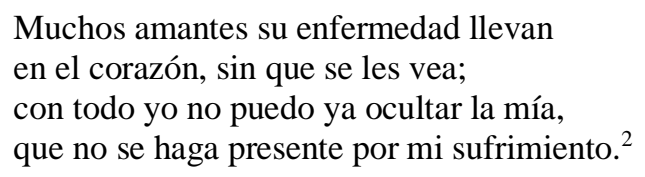

En parte inspirados por aquellos versos amorosos de franceses y sicilianos, comenzó a forjarse en Italia un "nuevo estilo" poético cuyos protagonistas pronto empezaron a ser conocidos como los stilnovisti, los poetas del dolce stil nuovo. Escribían siempre en lengua vernácula y dedicaban casi todos sus versos a la temática amorosa, pero sobre todo utilizaron su arte poética para adentrarse en los problemas filosóficos, espirituales y fisiológicos relativos al amor. El más renombrado protagonista de aquel nuevo estilo fue Guido Cavalcanti (c.1258-1300), autor de un poema destinado a convertirse muy pronto en objeto de sutiles comentarios. Parece ser que el amigo Guido Orlandi, en nombre de una dama, le envió un soneto invitándole a explicar la naturaleza del amor, "Onde si move e donde nasce Amore ". 3 Cavalcanti respondió escribiendo uno de los más famosos poemas de la historia de la literatura: el Donna me prega. Los textos, como las manifestaciones artísticas o cualquier otra expresión simbólica, están cargados de significados que en muchas ocasiones sólo pueden captar y entender quienes se hallan en un mismo contexto cultural. Con el tiempo no son pocas las veces que signo y significado se divorcian y nos impiden captar sus vínculos. Quedan los signos, pero o no sabemos interpretarlos o les atribuimos significados diferentes a los que tuvieron en su día. El poema de Cavalcanti puede parecer al lector contemporáneo una bella rima apasionada, digna de ser incluida en cualquier volumen de poesía amorosa. Pocos de nuestros contemporáneos, a excepción de unos pocos académicos especialistas en la poesía medieval, captan la multitud de significados y temas filosóficos, médicos y morales que yacen en esos versos. El poema de Cavalcanti ha sido objeto de una infinitud de exégesis. ${ }^{4}$ Una de las primeras, si no la primera, fue la que hizo su amigo Dino del Garbo (1280-1327), gracias a la cual podemos acercarnos a desentrañar sus poéticos, médicos y filosóficos significados. El comentario que hizo el florentino Del Garbo es tan detallado que resulta difícil separar cuánto hay en él de los pensamientos e intenciones de Cavalcanti y cuánto es una interpretación propia, de modo que aquí atribuiremos a ambos las mismas consideraciones sobre el amor. ${ }^{5}$

\footnotetext{
${ }^{2}$ En Alvar-Lucía (2008: 27).

${ }^{3}$ En Fenzi (1999: 78-79).

${ }^{4}$ Stone (2020).

${ }^{5}$ El comentario de Dino del Garbo está reproducido como Apéndice en Cavalcanti (1957: 359-78). Hay una excelente transcripción comentada en Bird (1940 y 1941) a la que nos referimos en este texto y donde se intentan desentrañar las diferencias entre ambos autores. Véase también Fenzi (1999). La única copia manuscrita que se conserva es de mano de Bocaccio y se encuentra en la Biblioteca Apostólica Vaticana, Codice Chigiano, L. V. 176, ff. 29r-32v. Cfr. Gagliano - Guérin - Zanni (2016).
} 
De Cavalcanti dijo Bocaccio que era “óptimo filósofo natural”, mientras que Giovanni Villani afirmó que Dino del Garbo "era grandísimo doctor en Física y en otras ciencias naturales y filosóficas. ${ }^{6}$ Ambos eran excelentes conocedores de las obras de Aristóteles, de Avicena, Averroes y en general de toda la tradición filosófica y científica. Todos aquellos conocimientos quedaron reflejados, condensados, en sus poemas y comentarios sobre el amor, los cuales se decantan por el análisis del amor sensual, dejando en un segundo plano tanto la acepción de amor como amistad como sus aspectos más metafísicos, espirituales o teológicos. El amor del que quieren hablar estos stilnovisti es un vehemente deseo de unirse con el objeto amado, una pasión tan violenta que altera el cuerpo llegando incluso a producir la locura o la muerte, de ahí que el amor deba ser tema de estudio tanto de los filósofos como de los médicos, los cuales denominan hereos a la pasión amorosa. ${ }^{7}$

Aristóteles, y más aún las interpretaciones que de él hizo Averroes, estuvieron en la base de las afirmaciones de estos protagonistas del dolce stil nuovo. Para el filósofo andalusí el ser humano posee tres facultades diferentes: vegetativa, sensitiva e intelectual. El intelecto es parte de una conciencia universal que se une con el cuerpo en el momento del nacimiento y retorna al universo tras la muerte, de modo que lo que proporciona a cada persona su identidad no es el intelecto, sino la particular e individual capacidad sensitiva, las pasiones y los deseos del cuerpo. ${ }^{8}$ Esto llevó a Averroes -y a muchos de sus seguidores- a considerar que el objetivo principal del ser humano era perfeccionar la capacidad sensitiva gracias a la razón, que deseos carnales e intelecto llegasen a un perfecto equilibrio, a un buon perfetto. ${ }^{9}$ Cavalcanti, tenaz estudioso de las obras de Averroes, no creía sin embargo que fuese posible alcanzar ese estado de buon perfetto y tal imposibilidad, pensaba, era la causa del continuo tormento que padece el hombre, siempre incapaz de gobernar sus pasiones con su razón. El amor era en buena medida el culpable de tal incapacidad. La lírica amorosa de Cavalcanti bien puede ser leída como una directa rectificación de la aspiración averroísta al equilibrio entre razón y pasiones.

Las "pasiones", como los "espíritus" se encuentran entre los términos que más variaciones semánticas han experimentado a lo largo de la historia del pensamiento filosófico y científico. Cuando Cavalcanti y Del Garbo afirmaban que el amor era una pasión, utilizaban el término en sentido aristotélico: aquello que perteneciendo al alma afecta al cuerpo, y por tanto sólo puede estar vinculada al apetito sensitivo, pues el apetito racional no interactúa con el cuerpo. Se referían, obviamente, a la parte sensitiva del alma, y más en concreto a la parte apetitiva que en ella se encuentra y que es la fuerza motriz del alma que se transmite al cuerpo. ${ }^{10} \mathrm{El}$ amor, como otras pasiones, pertenece a la facultad sensitiva del alma, que a su vez se divide en sentidos internos y externos. Los internos son el sentido común, la fantasía o imaginación y la memoria, mientras que los externos son los correspondientes a los cinco sentidos del cuerpo humano.

Tanto para Cavalcanti como para Del Garbo, no cabía duda de que el amor se asienta en la memoria, pues es allí donde se alojan las species que emanan de las cosas. Según la teoría aristotélica de la luz y la visión, especialmente desarrollada por la ciencia árabe medieval, la luz es la actualización del medio transparente, de lo diáfano, y la visión no es el resultado de la transmisión de una emanación material, sino un acto por el que se capta la forma de las cosas, no su materia. Tales formas de los objetos, desmaterializadas, son las species, que al llegar a los ojos nos permiten ver las cosas. Cavalcanti y Del Garbo recurrían a esta analogía entre la luz, la visión y el amor para mostrar que, así como las species emanadas de los objetos se plasman en la memoria, también es en la memoria del amante donde se alojan las species del objeto amado, generando el enamoramiento. El amor está en la memoria en tanto que esta comunica las species del objeto percibido al apetito, el cual genera la pasión amorosa. ${ }^{11}$ Esta es la

\footnotetext{
${ }^{6}$ Decamerón VI, 9; Villani, Historia Florentini X, xl, en Muratori (1723-51: vol. V. 10).

${ }^{7}$ Los estudios sobre el hereos, la enfermedad de amor, empezaron a desarrollarse especialmente con las investigaciones de Ciavolella (1976) y en los última años han sido objeto de un renovado interés. Véase la Introducción a Beecher-Ciavolella (1990), Wack (1990).

${ }^{8}$ Los estudios sobre el averroísmo son, como el lector puede imaginar, numerosísimos. Me remito aquí a una de las obras más recientes, donde los editores en su introducción y los autores de las contribuciones aportan una detallada bibliografía; me refiero a Akasoy - Giglioni (2013).

${ }^{9}$ Véase Blanco Valdés (2006).

${ }^{10}$ De anima I, 403a 17-19 y III. X, 433b 10-11.

${ }^{11}$ Bird (1940: 183-184) y Bird (1941: 146-147). Cfr. Robert (2014).
} 
explicación de uno de los temas recurrentes de toda la tradición médica sobre el amor: los ojos como órgano clave del proceso de enamoramiento. En palabras del propio Cavalcanti:

$$
\begin{aligned}
& \text { Por los ojos empezó el asalto } \\
& \text { que aniquiló toda resistencia, } \\
& \text { y así la mente quedó destruida. }{ }^{12}
\end{aligned}
$$

Cuando los ojos de una mujer se encuentran con los de un hombre, el amor en potencia se despierta y se convierte en pasión. Es entonces cuando se ponen en movimiento ciertos espíritus del cuerpo cuyo desenfreno provoca desequilibrios que pueden acabar degenerando en la enfermedad y hasta en la muerte. Cuando de los ojos del amante emanan con fuerza sus propios espíritus, como saetas, penetran por los ojos del amado y este cae presa del enamoramiento. Así escribía Cavalcanti:

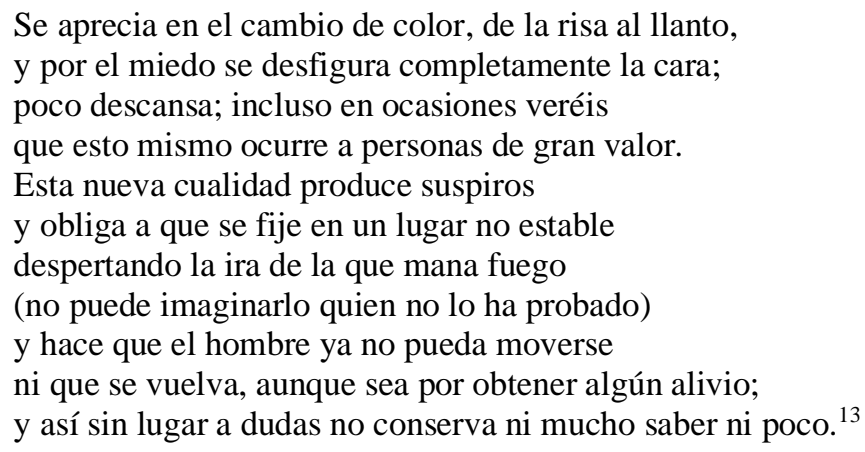

En cuanto a la pregunta acerca de cómo se genera el amor, la respuesta era doble. Había que tener en cuenta, en primer lugar, la disposición natural del cuerpo, por eso hay personas más predispuestas a amar que otras. Tal "disposición" se refería a la complexio, que es la proporción en la que se encuentran en un individuo las cuatro cualidades fundamentales (caliente, frío, seco y húmedo), que a su vez determinan la composición y equilibrio de los humores y estos, a su vez, los temperamentos. Además de la disposición natural de cada individuo, el otro desencadenante fundamental y necesario de la pasión amorosa eran las mencionadas species, su alojamiento en la memoria y su acción sobre el apetito o deseo.

Una de las características del enamorado, recordaban Dino del Garbo y Cavalcanti, es que oscila continuamente entre la euforia y la alegría y la tristeza y la desesperación. También en este caso la explicación de que así fuese residía en la fisiología aristotélica. El calor innato del corazón pone en movimiento la sangre y los espíritus vitales, haciendo que estos se expandan por todo el cuerpo y lo preparen para el movimiento. Cuando el individuo se encuentra ante algo placentero, el calor del corazón aumenta y en consecuencia se acelera la expansión por todo el cuerpo de los espíritus vitales. Por el contrario, cuando se encuentra ante algo desagradable o triste, el corazón se enfría y los espíritus se quedan en él. $\mathrm{O}$, en otras palabras, la causa de las pasiones y alteraciones del cuerpo es la diferencia de calor en el corazón, la cual hace que los espíritus se muevan ab extra o ad intra. ${ }^{14}$

La historia de la interpretación médica del amor es larga y se remonta a los tiempos de la Grecia clásica. Los médicos hipocráticos empezaron a describir algunos síntomas de pacientes que parecían muy enfermos y cuya causa atribuyeron al enamoramiento: visión ofuscada, sudores repentinos, palpitaciones irregulares o desmayos. ${ }^{15}$ Unos siglos después, Plutarco (s. I. d. de C.), convencido de que el amor tiene sede en el corazón, definió claramente la sintomatología del enamorado en su relato de los males padecidos por Antíoco y los intentos del médico Erasístrato por acabar con ellos. Cuando Estratónice

\footnotetext{
12 Alvar-Lucía (2008: 208). Véase también Guido Cavalcanti (2006: 33).

${ }^{13}$ Alvar-Lucía (2008: 200).

${ }^{14}$ Según Aristóteles, la rabia, la ira, no eran sino oleadas de sangre y calor en el corazón, y aunque no se refería explícitamente al amor, su modelo fue aplicado a él por quienes como Cavalcanti y Del Garbo pretendían dar una explicación del fenómeno amoroso en los términos de la filosofía natural y la fisiología aristotélicas. Aristóteles, Motu animalium vii, 701b20-32; viii, 201a1-7; Aristóteles, De Partibus animalium III, iv, 666a11, De anima I, i, 403a 30. Sobre la influencia de esta idea en Avicena y otros fisiólogos, cfr. Bird (1941: 132-3, 136-137).

${ }^{15}$ Véase McNamara (2015).
} 
entraba en la habitación de Antíoco, este comenzaba a manifestar palpitaciones irregulares del corazón, sudaba en exceso, se quedaba tremendamente pálido, tartamudeaba y veía todo borroso. Acabaría loco y muerto. ${ }^{16}$ Nacía así el concepto de "aegritudo amoris", que Galeno hizo suyo afirmando que si el amor era una enfermedad, era el médico quien debía estudiar sus síntomas, causas y métodos terapéuticos. ${ }^{17}$ El amor, decía, es una emoción humana, no divina, y puede llevar a una forma de locura. Para Galeno el amor no era una enfermedad del cuerpo, sino una pasión del alma, pero debemos tener en cuenta que según él las operaciones del alma eran el resultado de la composición humoral del cuerpo, tal como explica en su obra titulada Las facultades del alma siguen los temperamentos del cuerpo; de modo que en última instancia su interpretación de la enfermedad de amor era somática, aunque habrá que espera aún muchos siglos para que se especifiquen las características humorales de tal enfermedad. ${ }^{18}$

Haciéndose eco de la herencia griega y latina, fue la medicina árabe la que realmente empezó a considerar el amor como una enfermedad específica, ya no sólo como una variante de la melancolía o la manía. ${ }^{19}$ Así, por ejemplo, el médico persa Rhazes (o al-Razi) (ss. IX-X), en el capítulo V de su Kitāb al-Tibb al-Rühānī (Medicina del alma), identificó la enfermedad de amor, denominada cishq, con la forma más aguda de melancolía, la licantropía, una especie de locura que lleva al hombre a comportarse como un lobo (coturub). ${ }^{20} \mathrm{El}$ amor -decía- es una locura terrible que puede llegar a destruir al ser humano: al principio los amantes empiezan a cambiar su apariencia externa, se les debilita la vista, se les secan y hunden los ojos; se les seca también la lengua y en ella les salen llagas; finalmente se les seca todo el cuerpo y les asalta una sed terrible. Llegados a este punto, se pasan día y noche tumbados boca abajo o caminan entre las tumbas de los cementerios.

Fue en el siglo XI cuando las teorías de los médicos árabes sobre el amor empezaron a penetrar en el Occidente latino gracias en buena medida al trabajo de traducción de la escuela de Salerno, y más en concreto a los esfuerzos de Constantino el Africano (1058-87), que tradujo del árabe al latín el Kitab alMalaki de Ali ibn al Abbas al-Majusis -conocido a partir de entonces como los Pantegni- y el Zad almusafir de Ibn al-Jazzar, el famoso Viaticum. En este último, dividido en siete libros, la enfermedad de amor se describía así:

\begin{abstract}
Hereos es una enfermedad que padece el cerebro, y cuya causa es un gran anhelo acompañado de un intenso deseo sexual y aflicción de los pensamientos [...] Se trata de una enfermedad que tiene graves consecuencias para el alma. Aparecen incesantes pensamientos, los ojos siempre están como hundidos y se mueven rápidamente como persiguiendo al objeto de deseo. Los párpados se cierran y la piel amarillea, lo cual es debido al movimiento del calor que sigue a la falta de sueño. El pulso se acelera y hace irregular. Más cae el alma en este tipo de pensamientos, más dañinos se hacen los efectos para el cuerpo [...] Beber suave y buen vino es una de las mejores formas para alejar los pensamientos de estos enfermos de hereos, como lo es también charlar con los amigos, escuchar dulces melodías, contemplar agradables jardines y paisajes, ver correr el agua y contemplar el rostro de bellas mujeres. Ya dijo Rufus que el vino es la mejor medicina para el tímido, el triste y el heroico [el amante enfermo de hereos]. ${ }^{21}$
\end{abstract}

Descripciones muy similares se encuentran en otros médicos árabes, pero quizá una de las más relevantes, por la influencia que tuvo en la historia posterior de la medicina, fue la de Avicena. En el Libro III de su Canon dedicó unas páginas a los síntomas y diagnóstico de lo que él consideraba la enfermedad de amor, lo cual a partir de entonces legitimó la inclusión del amor entre los objetos de estudio de la medicina. Avicena describía tal enfermedad como una depresión de pensamientos obsesivos. Sus síntomas eran el descuido del aspecto personal, ojos hundidos y secos, parpadeos compulsivos y una continua alternancia de risa y llanto. La respiración también se veía afectada, siendo

\footnotetext{
${ }^{16}$ Este episodio relatado por Plutarco en su Vida de Demetrio (XXXVIII) se convertirá en representación icónica del mal de amores en las artes figurativas.

${ }^{17}$ Galeno dio una descripción detallada de la enfermedad amorosa de la esposa de Justus y en un comentario a los Pronósticos de Hipócrates (cap. 6) rebatió la idea de que el amor fuese una enfermedad de origen divino.

${ }^{18}$ Cfr. Wack (1990: 7-9).

${ }^{19}$ Wack (1990: 6-14), Giffen (1971).

${ }^{20}$ Abd Alghani (2014).

${ }^{21}$ Hay una transcripción del Viaticum I. 20, con una traducción inglesa, en Wack (1991: 179-193), donde se incluye un interesante fragmento sobre el uso y significado de los términos eros, heros y hereos. Véanse también las páginas que la misma autora dedica a la teoría del amor de Constantino el Africano en el cap. 2 de la misma obra.
} 
a veces muy rápida y otras muy lenta, el pulso se hacía irregular, los sudores excesivos y el enfermo padecía trastornos del sueño. Para realizar el diagnóstico, Avicena proponía que el médico verificase si el pulso se alteraba al escuchar el nombre de la persona amada. La curación podía consistir en la conjunción con esta última y en el caso de que ello no fuese posible se podía intentar que el enfermo se enamorase de otra persona que le hiciese olvidar a la anterior. También había que entretener al enfermo con paseos, juegos o charlas que le evadiesen de su obsesión. ${ }^{22}$

A las descripciones del hereos de Constantino el Africano y de Avicena siguieron, ya en el Occidente latino, las de otros médicos como Guglielmo de Saliceto (1210-1277) o de algunos de los integrantes de la escuela de Montpellier, como Gerard du Berry. Arnaldo de Villanova (1238-1311), alumno de Du Berry en Montpellier, en su Liber de amore heroico se detenía con detalle en los síntomas fisiológicos del hereos, explicándolos con los fundamentos de la medicina galénica. Así, por ejemplo, mantenía que si los ojos aparecían hundidos era porque se producía un extremo calentamiento de los espíritus del cuerpo que lo iban secando, llegando incluso a provocar un llanto sin lágrimas. Se hacía por tanto necesario aplicar terapias que combatiesen la sequedad y aportasen humedad al cuerpo, como los baños o la ingesta de vino, sumados, por supuesto, a todos los entretenimientos y cuidados ya propuestos por Avicena. También Bernard de Gordon (o Gordonius) se hacía eco de esta misma temática amorosa en su Lilium medicinae, insistiendo en la necesidad de explicar el proceso del enamoramiento y sus consecuencias basándose en la medicina galénica. ${ }^{23}$ Cuando un individuo en encuentra ante la presencia de un objeto o persona deseada se produce una especie de ebullición en la zona del corazón que hace que los espíritus vitales se recalienten y aumente su temperatura, incrementando también, en consecuencia, el calor de los espíritus animales que tienen sede en el cerebro y regulan las capacidades psíquicas y motoras. Este era el motivo, pensaban Gordon y Villanova, del desequilibrio de las facultades mentales que podía llevar a la locura y a la muerte: "nisi herosis succurratur in maniam cadunt aut moriuntur" [...] Amor est mentis insania, quia animus vagatur per inania, cerebro doloribus permiscens pauca gaudia", escribía. ${ }^{24}$ Gordon explicaba con los mismos procesos fisiológicos la causa de la sintomatología tradicional del amor: los picores, los ojos sin lágrimas, los temblores, el pulso irregular o la piel amarillenta.

Dino del Garbo y Cavalcanti acogieron todas estas interpretaciones médicas del amor, pero a diferencia de la mayoría de los médicos que acabamos de mencionar, ellos no creían que el amor fuese una enfermedad. Era cierto que éste podía provocar un agotamiento de la virtus vitalis de la que había hablado Avicena, pues al estar el amor relacionado con un excesivo calentamiento del corazón, se iban desequilibrando las cualidades del cuerpo, el enamorado dejaba de comer y su cuerpo comenzaba a secarse. Pero a pesar de ello el amor, escribía Del Garbo, no debía ser considerado como una enfermedad, pues no se trataba de un proceso "antinatural" en el sentido que la medicina galénica había dado a esta categoría, no se oponía a la complexio. Solo era una enfermedad, decía, "por accidente". Y no era una enfermedad en sí porque era el resultado de una acción natural de una facultad natural: del apetito sensitivo. ${ }^{25}$

¿Y la locura, la sinrazón? ¿Cómo podían derivarse de una pasión del apetito sensitivo? Porque el excesivo calor que se genera en el corazón enamorado, decían, puede llegar incluso a afectar a la facultad cogitativa, pues los espíritus vitales acaparan toda la atención del cuerpo, cuyo cerebro se hace incapaz de pensar en cualquier otra cosa que no sea el objeto de su deseo. Por eso, escribía Dino del Garbo, en el amor nunca puede haber sabiduría y por tanto nadie debería dejarse llevar por él. ${ }^{26}$ Ciertamente, el amor no pertenece al alma racional, pero a veces su inmensa fuerza puede oponerse a la razón. El apetito sensitivo no está regulado por la razón, escapa de su poder, y es entonces cuando la pasión amorosa degenera en locura. Además, al amor, bien lo había dicho Avicena, es connatural que su deseo sea

\footnotetext{
${ }^{22}$ Avicena (1987: 135-137). Sobre la teoría del amor de Avicena, veánse Fackenheim (1945), Chittick (2014).

${ }^{23}$ Existe una edición española contemporánea en dos volúmenes: Madrid: Arco-Libros, 1993. Véase también Cull - Dutton (1991), Lacarra (2015).

${ }^{24}$ Citado por Lowes (1914: 501, 502).

${ }^{25}$ Bird (1941:124-125), donde se hace notar que esta idea ya había sido formulada por Arnaldo de Villanova. Cfr. Lowes (1914: 497).

${ }^{26}$ Bird (1941:122).
} 
infinito, violento, sin límites, nunca satisfecho, siempre impidiendo acercarse a ese buon perfetto averroísta. El amor, en suma, es siempre fuente de sufrimiento. ${ }^{27}$

Una concepción diametralmente opuesta del amor salió de la pluma de otro de los protagonistas del dolce stil nuovo: Dante Alighieri (1265-1321), entrañable amigo de Cavalcanti, tanto como feroz crítico de sus ideas. Si sus amigos stilnovisti habían percibido y explicado el amor como una perturbación contra la cual la razón nada puede hacer, una pasión que aleja al hombre de toda posible racionalidad y conduce al sufrimiento, para Dante, en cambio, el deseo erótico es la manifestación de una fuerza vital que invade todo el universo dotándolo de vida ${ }^{28}$. El amor queda despojado de esa percepción nefasta, oscura, casi mortal de la que hablaban Cavalcanti o Del Garbo para convertirse en fuente de gozo, esplendor y sabiduría. El objetivo de Dante era hacer un retrato filosófico del amor que lo que lo alejase de ese exilio a la irracionalidad al que lo habían enviado sus queridos amigos poetas -y médicos- amorosos. Solo lo consiguió separando el amor del cuerpo, descarnándolo, alejándose de la tradición médica, espiritualizando. El amor por una mujer, por sus cualidades concretas y carnales, se transforma en el amor por una "mujer Filosofía". La "donna gentile" que tiene ante sus ojos y de cuyos ojos emanan rayos inflamados, es en realidad pura apariencia tras cuyos velos se esconde el más elevado conocimiento. ${ }^{29} \mathrm{El}$ verdadero amor es una forma de elevación a la divinidad, pues amando a Beatrice, el poeta alcanza el conocimiento de Dios.

La concepción dantesca del amor es una reconciliación con el buon perfetto averroísta. Contra la condena cavalcantiana del amor como fuerza obstaculizadora de la razón, y por tanto fuente de sufrimiento, Dante cree que el amor siempre está gobernado por el "fiel consejo de la razón", lo cual está en consonancia con su objetivo de aspirar a un control racional de todas las pasiones. En Dante la razón vence sobre el amor porque el propio amor es racional. Con estas bellas palabras lo expresará en su Convivio (III, iii):

\footnotetext{
dije que amor me hablaba en la mente, para dar a entender que este amor era el que nace en aquella nobilísima naturaleza, es decir, de la verdad y la virtud, para excluir de mí toda falsa opinión, por la cual se sospechase que mi amor fuese tal por deleite sensible. ${ }^{30}$
}

\section{El amor filosófico renacentista}

Los siglos XV y XVI estuvieron invadidos por una oleada de tratados filosóficos sobre el amor que se inspiraban fundamentalmente en el pensamiento de Marsilio Ficino, en cuya obra estaba muy presente la antigua división platónica entre amor profano o sensual y amor filosófico o divino. ${ }^{31}$ Para Ficino el amor tiene un valor filosófico y cosmológico, es vínculo del universo, vehículo de unidad de todas sus partes. El tema del amor recorre toda su obra y, como Platón, se inclina siempre por una defensa del amor cognoscitivo, divino, con una insistente desconfianza por el amor carnal. Ejemplar en este sentido son sus palabras en el De vita coelitus comparanda:

\footnotetext{
${ }^{27}$ Bird (1941: 129), Avicena (Canon III, Fen. I. Tr. IV, cap. 23, vol. 1, p. 494a).

${ }^{28}$ Divina Comedia, Paraíso I, 103-120; Convivio, III, iii, 2-5.

${ }^{29}$ Cfr. Fenzi (1999: 18), Corti (1983).

${ }^{30}$ Véase también La Vida nueva, II, donde se lee: "Y aunque su imagen, que continuamente me acompaña, se enseñorease de mí por voluntad de Amor, tenía tan nobilísima virtud, que nunca consintió que Amor me gobernase sin el consejo de la razón en aquellas cosas en que sea útil oír el citado consejo". La poesía filosófica amorosa de Dante recibió una durísima crítica por parte de Cecco D’ Ascoli (Francesco Stabili) (1269-1327) en su largo y enciclopédico poema La Acerba. Cecco defiende una naturalización radical de todos los fenómenos del universo, incluidas todas las pasiones humanas, que según él han de ser explicadas con causas naturales y no con quimeras intelectualizadas, teológicas y espirituales como había pretendido en Dante. También el amor es considerado un proceso natural cuya causa primera reside en los astros, que continuamente determinan su decurso. El amor escapa, por tanto, a la voluntad humana, cuya fuerza nada puede contra el poder de los astros. Cecco despreciaba sin ambages la mistificación del amor y ensalzaba todas las bondades y placeres que el amor profano regalaba a quien cayese en sus brazos. Cfr. Acerba, Libro III, cap. 1, 1-24 y Libro III, cap. 1, 85; Crespi (1929), Fabian (2014).

${ }^{31}$ Cfr. Nelson (1958: 67-162).
} 
Para quien se dedica a la contemplación y es ávido de saber, nada hay más dañoso que el acto venéreo y, a la inversa, para quien se dedica a éste de continuo nada puede haber más ajeno que la investigación y la contemplación. ${ }^{32}$

Quien busca la verdad, decía, se enfrenta a tres monstruos terribles. Además de la tendencia del sabio a la melancolía como resultado de su continuo descuido del buen equilibrio de su pituita y su bilis negra, esos tres monstruos siempre acechan. El primero de ellos era "el coito al que incita Venus", que seca inmediatamente los espíritus, debilita el estómago y las partes situadas en torno al corazón y es completamente nocivo para el ingenio. El segundo monstruo es el exceso de vino y comida y el tercero la falta de sueño, acostarse demasiado tarde y hacerlo después de cenar. ${ }^{33}$

De la larguísima producción literaria de Ficino, fue su Commentarium in Convivium Platonis de Amore, escrito en 1469 e impreso en 1484, el que mayor inspiración y comentarios despertó entre los filósofos del siglo XVI. Traducido por él mismo al italiano como el De Amore, es un gran elogio del amor que trasciende lo carnal y se eleva hacia el conocimiento de la divinidad, mientras que el amor puramente humano, el amor profano, es engañoso y vil, como lo son todas las cosas sensibles. Sin embargo, la apuesta ficiniana por ese amor que aspira al conocimiento de lo bello y lo divino no excluía su buen conocimiento de las supuestas bases fisiológicas del fenómeno amoroso. Es más, las utilizaba como argumento fundamental para poner sobre aviso a quienes cayesen en las tentaciones del deseo carnal. En el discurso séptimo del De amore (cap. 3) se asocia el amor con la locura, considerándolo una enfermedad humana que convierte al hombre en una bestia, un amor bestial que es fruto, explica Ficino, de un proceso fisiológico. ${ }^{34} \mathrm{Y}$ en el capítulo 7 del mismo canto, matizaba su convicción de que el amor humano es una perturbación de la sangre:

La prueba de que esta pasión está en la sangre es que este ardor carece de reposo, y los físicos establecen esta fiebre continua en la sangre; la que cesa en seis horas, en la pituita; la que cesa en un día, en la bilis, y la que cesa en dos, en el humor de la bilis negra. Con razón ponemos, entonces, la fiebre del amor en la sangre, o sea, en la sangre melancólica, como oísteis en el discurso de Sócrates, pues a esta sangre acompaña siempre una idea fija. ${ }^{35}$

Como enfermedad que era, el amor debía ser tratado por el médico, con una terapia que iba desde las sangrías para eliminar la sangre perturbada a la buena costumbre de tomar vino claro, hacer ejercicio para sudar o tener la mente distraída. Pero sobre todo era importante seguir férreamente una advertencia: "esquivar los ojos del amado". ${ }^{36}$ Una cosa destacaba en la explicación ficiniana de la fisiología del amor: su insistencia en la acción de los spiritus. No era en absoluto una novedad, pero la insistencia de Ficino en esta cuestión supera con creces las de otros autores e introduce variaciones muy significativas. El canto VII del De amore se abre con una alusión a Cavalcanti y si bien parece que sus explicaciones coinciden, especialmente en lo que se refiere a la idea de que el amor penetra por los ojos, para Ficino los espíritus que salen de los ojos no son meras species, formas sin materia, sino los propios espíritus vitales del cuerpo:

\footnotetext{
Pues como los espíritus (spiritus) se generan de la sangre más pura por el calor del corazón en nosotros son siempre semejantes al humor de la sangre. Pero al igual que este vapor de los espíritus (spiritus) nace de la sangre, así también manda fuera rayos semejantes a sí por los ojos, como a través de ventanas de vidrio. Y también, como el sol que es el corazón del mundo expande en su curso la luz y por la luz difunde sus virtudes a las regiones inferiores, así el corazón de nuestro cuerpo, agitando la sangre próxima a él en su movimiento eterno, desde él extiende los espíritus (spiritus) a todo el cuerpo. Y a través de aquéllos difunde las chispas de luz de los rayos a cada miembro, sobre todo a través de los ojos. [...] ¿Qué tiene de sorprendente entonces si el ojo abierto, y dirigido con atención hacia alguno, lanza a los ojos del que está cerca las flechas de sus rayos, y junto con éstas, que son el vehículo del espíritu (spiritus), extiende el vapor sanguíneo, que llamamos espíritu (spiritus)? De aquí la flecha envenenada traspasa los ojos y como es lanzada por el corazón del que hiere, busca el pecho del hombre herido, como su propia morada, hiere su
}

\footnotetext{
${ }^{32}$ Ficino (2005:76).

${ }^{33}$ Ficino (2005: 31).

${ }^{34}$ Ficino (1994: 198-199).

35 Ficino (1994: 210).

${ }^{36}$ Ficino (1994: 216-217).
} 
corazón y se condensa en su más duro dorso, y se convierte en sangre. Esta sangre extraña, que es ajena a la naturaleza del herido, envenena la sangre propia de éste. Y envenenada la sangre, se enferma. ${ }^{37}$

Los espíritus corporales de los que hablaban los médicos eran, según Ficino, los primeros instrumentos del alma incorpórea y eterna, la herramienta con la que poder abarcar todo el universo. ${ }^{38}$ Pero si bien es cierto que los espíritus de los que hablaba Ficino entroncaban con la tradición médica hipocráticogalénica, no se limitaban a ella, pues en este caso eran inseparables de funciones y valores metafísicos, teológicos y cosmológicos. ${ }^{39}$ Los espíritus vinculan el mundo de lo inteligible, inmaterial por esencia, con el mundo terrenal material, al hombre con el gran animal que es el mundo. Ambos poseen un spiritus que constituye el vínculo del universo. Vínculo que ya había hecho su presencia en el Tratado sobre el amor de Avicena, pero también en los versos de Dante, y que en el siglo XVI gozará de una nueva fortuna gracias a su reinterpretación en clave platónica y hermética, baste recordar como ejemplo el $D e$ vinculis in genere de Giordano Bruno (1591).

Giovanni Pico della Mirandola (1463-1494) siguió la concepción platónica del amor expuesta por Ficino y en el Commento alla Canzone di Girolamo Benivieni dividió el amor en tres tipos: angelical, humano y bestial, insistiendo en su desinterés por el amor vulgar, que consideraba un apetito sensitivo correspondiente a la parte más inferior del alma y debía ser dominado por el amor racional. En la misma línea neoplatónica de defensa de un amor racional y metafísico se expresó León Hebreo (1460-1530) en sus Dialoghi d'amore (publicados póstumamente en Roma, 1535) que serían traducidos al castellano por Garcilaso de la Vega en 1590. A León Hebreo tampoco le interesaba el amor profano, carnal, vulgar, y cuando hablaba de amor humano solo lo hacía refiriéndose al amor que el hombre siente por Dios (el amor divino es el que el Creador siente por lo creado). Solo se salvaba de sus condenas, en todo caso, un amor carnal moderado por el intelecto y dirigido exclusivamente a la reproducción, mas nunca al placer.

Entre finales del siglo XV y principios del siglo XVI, las obras de Ficino y León Hebreo sobre el amor se convirtieron en modelo y punto de referencia para toda una larga lista de autores neoplatónicos que heredaron una profunda expresión de recelo y desinterés, cuando no de directo desprecio, por el amor carnal, vulgar. Uno de ellos fue el discípulo de Ficino, Francesco Cattani da Diaceto (1466-1522), que insistía en que el amor carnal solo es fuente de ignorancia y enfermedad. ${ }^{40}$ Pietro Bembo (1470-1547), por su parte, llevó el discurso amoroso hacia el terreno literario, uniendo platonismo y petrarquismo. Su reflexión sobre el amor está destinada a enseñar al lector a no errar, pues dado que no amar es imposible, el hombre, dice, ha de hacer todo lo posible para dominar ese amor humano, lleno de deseo y tormentos, y elevarse al amor divino, que es la auténtica satisfacción para el alma. Se trataba, en el fondo, de una cristianización del amor. ${ }^{41}$ Pocos años más tarde, en 1525, Mario Equicola (1470-1525) publicó su Libro de natura de amore, una obra de carácter enciclopédico donde se hacía un repaso por todos los tipos de amor, del cortesano al divino, del carnal al metafísico, para concluir afirmando que todos los tipos de amor son en el fondo formas de amor a sí mismo y que este amor a sí mismo conduce al amor a Dios. ${ }^{42}$

Los ecos del amor ficiniano siguieron muy vivos durante todo el siglo XVI. En 1556 Flaminio Nobili publicó su Trattato dell'Amore Humano, cuyo objetivo era desentrañar el vínculo entre los dos tipos de amor de la tradición filosófica neoplatónica, el amor carnal y divino. Para ello escogió la categoría de "amor humano" como nexo intermedio de unión entre ambos. En un tono muy similar al de Equicola, afirmaba que el amor humano siempre es honesto si se mantiene en el plano intelectual, pero se convierte

\footnotetext{
${ }^{37}$ Ficino (1994: 200-203). Sobre el complejísimo concepto de spiritus en el pensamiento filosófico científico medieval véase Fattori Bianchi (1984), Gubbini (2020). Para la misma cuestión en el Renacimiento y los orígenes del pensamiento moderno: Bono (1984), Granada (1984), Hirai (2005). Y por supuesto el clásico estudio sobre el concepto de pneuma de Verbeke (1945). Sobre la interpretación que Ficino hace de Cavalcanti, véase Ludueña (2019).

${ }^{38}$ Ficino (2005: 25),

${ }^{39}$ Ficino (2005: 95-96).

${ }^{40}$ Fellina (2017).

${ }^{41}$ Dionisotti (1966). Bembo será uno de los personajes de Il Cortigiano de B. Castiglione, encargado de exponer la condena del amor profano.

${ }^{42}$ Moulton (2015).
} 
en algo bestial cuando es presa de los sentidos. ${ }^{43}$ Podríamos seguir la larga lista con las lecciones que Francesco de' Vieri preparó para ser leídas en la Academia florentina. Todo ello sin olvidar, por supuesto, las Conclusioni amorose de Torquato Tasso (1570), un auténtico compendio de la literatura platónica sobre el amor de todo el siglo XVI.

No todos los platónicos, sin embargo, quisieron abrazar un amor puramente contemplativo. El amor del sabio ermitaño que encuentra el joven Lavinello en Gli Asolani de Bembo estaba muy lejos de la real vida cortesana en la que se movían los intelectuales de la época, incluido el propio Bembo. El gusto renacentista por la "civil conversación", la conversación ingeniosa sobre temas como la galantería, el amor o las buenas maneras, vino en ayuda de una conciliación entre platonismo y vida cortesana, lo cual quedó reflejado en la estructura dialógica de la mayoría de los textos sobre el amor que se escribieron en el s. XVI. ${ }^{44}$ El Cortesano de Baldassare Castiglione (1478-1529), publicado en Venecia en 1528, pronto se convirtió en el mejor ejemplo a seguir por quienes pretendían llevar a cabo aquella conciliación. ${ }^{45}$ En su libro IV Castiglione ofrecía el contrapunto al enfoque metafísico e intelectualizado del amor expresado por Bembo, en cuanto que reconocía la centralidad y valor del amor mundano en la virtuosa vida de la corte. ${ }^{46}$ Según Bembo, al que Castiglione concedía el papel de uno de los protagonistas del diálogo, el cortesano se debía elevar sobre el amor sensual. ${ }^{47}$ Mas Castiglione con gran sutileza retórica mostraba que él se inclinaba más por el platonismo florentino de Ficino que por el extremismo espiritualizante de Bembo, el cual no hacía ninguna concesión al amor sensual. ${ }^{48} \mathrm{La}$ estrategia utilizada para mostrar su crítica a Bembo esa elegante y divertida. Se relataba cómo habiendo hablado Bembo:

con tanta fuerza que casi parecía estar arrebatado y fuera de sí, se quedó sin hacer movimiento ninguno, teniendo los ojos vueltos hacia el cielo como atónito, cuando Emilia, la cual juntamente con todos los otros había estado siempre atentísima, tirándole la halda, le dixo: "Guardà, miser Pietro, que a vos también con esos pensamientos no se os a parte el alma del cuerpo. ${ }^{49}$

La obra de Castiglione tuvo un gran éxito desde que vio la luz en Venecia. De ella rápidamente se hicieron otras ediciones y se tradujo a varias lenguas, al español, inglés, francés, alemán, polaco y por supuesto al latín. ${ }^{50}$ Recogiendo en buena medida el testigo de El Cortesano, en los ambientes intelectuales florentinos y venecianos de mediados del s. XVI se produjo una oleada de obras sobre el amor escritas por autores que aún estando teñidos de concepciones neoplatónicas prefirieron concentrarse en cuestiones populares, cortesanas y pedagógicas. Entre ellos encontramos el Specchio d'amore de Bartolomeo Gottifreddi (Florencia 1547), el Dialogo amoroso y el Raverta de Giuseppe Betussi (Venecia 1542 y 1543). En la misma línea estaba la obra de una mujer: Tullia D’Aragona, una de las más famosas cortesanas de la época, que en 1547 publicó un Dialogo atacando la visión puramente intelectual y metafísica del amor. ${ }^{51}$ Una mención especial merece la obra de Francesco Sansovino titulada Ragionamenti di messer F. Sansovino, nel quale s'insegna a'giovanni uomini la bella arte d'amore (1545). Este último fue el que con más dureza criticó los planteamientos que los platónicos habían hecho del amor y su desdén por el amor humano, sensual. ${ }^{52}$ Tanto por el estilo literario como por las ideas que circulan a lo largo de las páginas de

\footnotetext{
${ }^{43}$ Maggi (1999), Musacchio (1992).

${ }^{44}$ Cox (1992), Maier-Kaapoor (2010: 122-123).

${ }^{45}$ En realidad, Castiglione escribió el libro en los primeros años del s. XVI y el manuscrito tuvo una gran difusión. Sólo tomó la decisión de publicarlo en los años finales de su vida, cuando era nuncio papal en España.

${ }^{46}$ Castiglione (2011: IV, 50: 507, IV, 51: 508-509). Se cita aquí por la edición española de 2011, cuya paginación está indicada a continuación del libro y el capítulo. Bembo, que era amigo de Castiglione, no se tomó a mal la ironía, de hecho, su intervención fue capital para convencer al canciller de la República de Venecia, Giovanni Battista Ramusio, de que permitiese la publicación de la obra. Tras la muerte de Castiglione en 1529, encontrándose en Toledo, Bembo le dedicó un epitafio.

${ }^{47}$ Cfr. Di Giulio (1996).

${ }^{48}$ Maier-Kaapoor (2010: 188-207).

${ }^{49}$ Castiglione (2011: IV, 7: 533-534).

${ }^{50}$ Burke (1998).

${ }^{51}$ Leushuis (2017: 108-170).

${ }^{52}$ Todos estos diálogos están recogidos en Zonta (1912). La lista sería bastante más larga, pero basten aquí, como modelo, estos casos citados.
} 
la obra, se encuentran en el texto de Saansovino muchos paralelismos con Il Delfino de Patrizi del que hablaremos a continuación. Así, por ejemplo, se podía leer en el Ragionamento:

Silio: ¿Qué gente es esa que no aprecia el amor de las bellas mujeres, ya sean nobles o no?

Panfilo: Son los platónicos, es decir, los contempladores de la belleza más perfecta con la cual ascienden a la divinidad. Pero dejémosles ir, que son sospechosas sus acciones. ${ }^{53}$

\section{Una filosofía natural del beso: Il Delfino, overo del bacio de Patrizi.}

Francesco Patrizi da Cherso es uno de los grandes olvidados de la historia del pensamiento filosófico y científico. Un olvido que contrasta enormemente con la relevancia que sus ideas tuvieron no solo estando él en vida, sino llegando incluso a las mentes de muchos de los protagonistas del clima intelectual del s. XVII. Exceptuando los maravillosos estudios que un puñado de historiadores le han dedicado, el nombre de Patrizi, cuando aparece, lo hace vinculado a su Nova de Universis Philosophia (Venecia, 1591), una obra ciertamente magna, mas tardía, escrita casi al final de su vida. Enciclopédica, de lectura ardua, la Nova de Universis Philosophia fue el resultado maduro de la actitud crítica con el aristotelismo de las escuelas, del perfil humanista y la fascinación por el platonismo y el hermetismo que empezaron a germinar en la mente de Patrizi desde su juventud y fueron evolucionando en su paso por las universidades y ambientes intelectuales de Padua, Venecia y Ferrara. ${ }^{54}$ En una carta autobiográfica, el propio Patrizi contaba que fue en sus años de juventud como estudiante en la Facultad de Artes y Medicina de la Universidad de Padua donde empezó a sentir sus simpatías por un averroísmo de tintes platónicos que enseñaban algunos de sus maestros, como Marcantonio de' Passeri, apodado "il Genoa". 55

De los años que Patrizi transcurrió en Padua nació en 1553 su primera obra impresa, un volumen que contenía cuatro textos: La città felice; Il Dialogo dell'Honore, il Barignano; una Lettura sopra il Soneto del Petrarca y un Discorso della diversità de' furori poetici. La città felice es una demostración de concordismo entre Aristóteles y Platón: por una parte, la defensa de una ética aristotélica de la virtud y la felicidad, una concepción aristocrática de la organización política; por otra parte, una concepción astrológica del mundo que permitía a Patrizi ofrecer una fundamentación naturalista de un modelo de ciudad gobernada por una élite aristocrática y astrológicamente determinada. El orden de la ciudad, la estructura aristotélica de la polis, resultaba ser indisociable de la filosofía natural, pues las necesidades de la ciudad y de los ciudadanos -se leía en el texto- se deducían de forma necesaria de las exigencias requeridas para la conservación de los espíritus que según la tradición hipocrático galénica eran los responsables últimos de todas las funciones del cuerpo humano. ${ }^{56}$ En el Discorso della diversità de' furori poetici, Patrizi desarrollaba uno de los temas más amados por los nuevos platónicos: la teoría de furor, vinculándola a una concepción animista y unitaria del cosmos de corte ficiniano. ${ }^{57}$

Abandonada la Universidad de Padua en 1554 y tras una breve estancia en su Cherso natal, en 1557 Patrizi decidió instalarse en Venecia. Se encontró una ciudad en plena efervescencia política y cultural, donde tuvo además la suerte de llegar casi al mismo tiempo que se creaba la Accademia della Fama, fundada por Federico Badoer en $1558 .^{58}$ En el seno de la Academia, Patrizi se sintió fascinado por el hermetismo neoplatónico de Francesco Giorgio -también conocido como Zorzi (1466-1540)- y de Giulio Camillo Delminio (1480-1545), autor de un famoso "teatro de la memoria" diseñado no solo para recordar, sino como auténtica máquina de descubrimiento y desvelamiento de la verdad. ${ }^{59}$ La meta del

\footnotetext{
${ }^{53}$ Zonta (1912: 165).

${ }^{54}$ Se citan a continuación sólo algunos de los principales trabajos sobre el pensamiento de Patrizi: Arcari, (1935), Bolzoni (1980), Castelli (2002), Dadic (2000), Muccillo (1986), Plastina (1992), Prins (2015), Puliafito (1987), Vasoli (1989).

55 Patrizi escribió aquella carta, enviada a Baccio Valori, en 1587, está publicada en Patrizi (1975: 45-51).

${ }^{56}$ Véase Gómez (2015), Bolzoni (1980: 38-46); Arcari (1935: cap. 2), Castelli (2002: 21-27).

${ }^{57}$ Pattini (2002: 81-119); Gentile (1983: 33-77).

${ }^{58}$ Véase Gómez (2020: 357-382). Sobre la Academia de la Fama, véase Bolzoni (1981), Rose (1969), Pagan (1973-1974), Tafuri (1985: 172-185).

${ }^{59}$ Sobre F. Giorgio, véase Vasoli (2005). Un detallado estudio de las fuentes de Francesco Giorgio se encuentra en la edición del De harmonia mundi realizada por Campanini (2010).
} 
teatro de Camillo era hacer descansar la retórica y la elocuencia en los fundamentos de una metafísica neoplatónica y hermética que transformaba también la teoría del conocimiento ${ }^{60}$ En 1560 Patrizi se encargó de parte de una nueva edición de las obras de Camillo, en concreto del tomo sobre retórica, tópica y poética. Partiendo de una concepción cratiliana del lenguaje, el Chersino estaba convencido de que la retórica, lejos de ser un puro arte de los signos o un ejercicio de imitatio de los antiguos, debía estar encaminada a capturar las proporciones, esencias y estructura del cosmos. ${ }^{61}$

Patrizi quiso poner en práctica su concepción de la retórica en sus comentarios a los sonetos amorosos de su amigo Luca Contile. Lo hizo en Le Rime di Messer Luca Contile (Venecia, 1560), donde recurría a la tópica para analizar con ella cada una de las palabras de los sonetos y desvelar así el auténtico significado del argumento central: el amor humano y cosmológico. Bajo la apariencia de esas rimas amorosas y cortesanas tan de moda en la época, yacía, según Patrizi, el minucioso trabajo de la inventio que, movida por el ingenio, iba hilando cada palabra con su concepto, y en cada uno de ellos se volvían a desplegar más vocablos y conceptos, como en un río de sabiduría capaz de reflejar los más profundos y ocultos secretos de los vínculos amorosos. La poesía no era mera elocuencia, mera estética, sino el verdadero "poema del mundo". O al menos, así lo pensaba Patrizi, tal debía ser.

Patrizi no solo vio en los sonetos de Contile la ocasión para ensayar su proyecto de una retórica filosófica. Los utilizó también para lanzarse a la arena de la reflexión sobre la filosofía y la fisiología del amor. Todas las tradiciones que se habían ido tejiendo hasta entonces tenían su eco en los sonetos de Contile: la luz, los ojos, la belleza y el conocimiento de las verdades más elevadas, pero también los temblores, la palidez del rostro, el deseo que lleva sin freno a la locura, la aegritudo amoris, el mal del amor, el hereos. Y también los besos, a cuyo estudio, decía Patrizi en unas líneas de su comentario a las rimas de Contile, ya había dedicado algún tiempo. ${ }^{62}$ Se refería a un trabajo que reposaba silencioso en sus estancias y que estaría destinado a seguir oculto durante siglos. Se trataba de Il Delfino, overo del bacio, un texto manuscrito conservado en la Biblioteca Ambrosiana de Milán y del que solo en 1975 se hizo una edición impresa. ${ }^{63}$ Se desconoce la fecha de su redacción, aunque evidentemente, por la referencia en Le Rime, debió ser escrito antes de 1560, muy probablemente durante su estancia veneciana. Además, el estilo irónico, casi burlesco, en forma de diálogo, coincide con sus obras del mismo periodo, desde La Città felice al Della Historia (1560) o el Della Retorica (1562) y se aleja, en cambio, de la prosa densa de sus obras posteriores, como las Discussiones peripapeticae (1571 y 1581), Della poetica (1586) o la propia Nova de Universis Philosophia.

A primera vista, Il Delfino podría parecer uno más de los muchos textos de las tradiciones literarias, médicas y filosóficas sobre el amor que, como hemos visto, se habían ido desarrollando a lo largo de los siglos. Mas el texto de Patrizi, teniendo elementos de todas esas tradiciones, se diferencia de todas ellas. Destaca en especial la gran crítica que un apasionado platónico comon lo era él hizo a los discursos neoplatónicos sobre el amor y al desprecio que estos habían expresado por el amor sensual. En Il Delfino, Patrizi lleva al límite la descripción ficiniana del proceso de enamoramiento basada en la tradición médica hipocrático-galénica, la fisiología de los humores y los espíritus, uniéndola a elementos fundamentales de la filosofía natural de corte platónico y hermético. No hay nada en él, sin embargo, que apunte a la definición de tal proceso fisiológico como una enfermedad, siempre y cuando la generación y funcionamiento de los espíritus del cuerpo se mantengan en buena forma y equilibrio. Es

\footnotetext{
${ }^{60}$ Sobre Camillo, véase Yates (2005), Stabile (1974), Bolzoni (1984, 2007, 2015).

61 Gómez (2020).

62 "Non può parimenti verun'altro che amante, giudicare la soavità dello assaporamento. Il quale si pruova nel bacio, in quelle tante maniere, che è stato da me in altro tempo divisato", Patrizi (1560: 17r).

${ }^{63}$ Il Delfino overo del bacio, Biblioteca Ambrosiana de Milán, Códice Q 119 Sup., ff. 106r-117v. Se trata de una copia del texto original de Patrizi, realizada en el s. XVI, a la que el propio Patrizi añadió algunas anotaciones de carácter fundamentalmente estilístico. El códice que lo contiene incluye también diversos opúsculos de diferentes autores que tratan en su mayoría de cuestiones matemáticas. Sobre este códice véase Kristeller (1963-67: I, 308, 309). Véase también Rivolta (1933: 58-60). Hay una edición de Aguzzi Barbagli en Patrizi (1975: 133-164). Esta edición especifica las expresiones que figuraban en la copia de algún secretario y que posteriormente Patrizi revisó y tachó. Véase también Aguzzi-Barbagli (1972).
} 
precisamente en este momento crítico del enamoramiento cuando intervienen los besos, pue ellos son los encargados de la regeneración de los espíritus.

El texto de Patrizi es un encantador y divertido diálogo sobre la naturaleza de los besos y sus diferentes tipos: en la mano, en el cuello, en las mejillas, en el pecho, con lengua o sin ella, de chupetón o de leve roce en la piel. Una auténtica clasificación de los besos a partir de la cual Patrizi, con gran ironía y un humor no exento de guiños retóricos a otros autores, va desgranando su idea de en qué consiste el amor, carnal o celeste. Todo comienza cuando el joven Delfino, a quien a lo largo de todo el diálogo se le llama "Angelo amoroso", acude al encuentro de Patrizi para que le ayude a resolver sus grandes dudas acerca de qué es el amor. Este, que habita en la soledad de una alta colina, le responde: "No creo que haya sido buena idea la vuestra, Señor Angelo Amoroso, ésta de venir a preguntar sobre el amor a hombre ermitaño y dedicado a estudios bien diferentes a los amorosos, que bien sabéis que éstos, en la apartada vida en soledad, no han de tener cabida." ${ }^{64}$

Se disparaba así, para quien supiese captar la referencia, la primera lanza de tono burlón dirigida contra los discursos neoplatónicos sobre el amor, pues el sabio anacoreta, escondido en su solitario refugio, apartado de los amores carnales y absorto en la contemplación de las más elevadas ideas, era el retrato filosófico de los nuevos platónicos. Era una alusión retórica al episodio de Lavinello relatado por el platónico Bembo en Gli Asolani. ${ }^{65}$ Patrizi, en cambio, comienza su diálogo subrayando que el tema del amor no es muy adecuado para un ermitaño. No quiere esto decir que no haya mucho de neoplatonismo en Il Delfino, pero nos encontramos ante un caso similar al de La ciudad feliz, pues si en ella exponía un proyecto de naturalización de la organización política del estado propuesta por Aristóteles, en este caso el proyecto es una naturalización del amor y una defensa del amor carnal que le alejaban de los discursos metafísicos de corte platónico. Tras afirmar que el tema del amor es poco adecuado para quien vive alejado del mundanal ruido, Patrizi decide que va a hablar por boca de un "espíritu amoroso" que siente que se le acaba de meter en el cuerpo.

Comienza así la inquisición de Delfino sobre los besos. Y su primera pregunta es qué los hace tan dulces, un misterio para el que nunca ha encontrado respuesta en ningún escritor. ${ }^{66}$ Patrizi rápidamente le hace notar que no todos los besos provocan dulzura o ternura en quien los recibe. Por ejemplo, y así Delfino lo reconoce, los besos dados por familiares o los recibidos en la frente o las mejillas no despiertan tales sensaciones, y por tanto no todo beso es dulce. O, en otras palabras, el beso no es dulce en si mismo. Pronto se desvela que lo que intriga e inquieta a Delfino es en realidad la cosquilleante dulzura que provoca el beso en la boca, el beso amoroso. Mas, pregunta Patrizi, ¿y si el asunto amoroso en cuestión fuese con una mujer fea, vieja o con mal aliento? "Una dulzura tal quédesela quien quiera, que a mí no me interesa", es la tajante respuesta de Delfino. Parece entonces que ya vamos por buen camino: lo que produce dulzura es la belleza. Aunque también es cierto, recuerda Patrizi, que hay bellísimas cortesanas que en sus tratos amorosos con apuestos mancebos rehúyen los besos, que parecen despertar en ellas más asco que dulzura. De modo que tampoco en la mera belleza del cuerpo puede residir la respuesta al interrogante de Delfino. ${ }^{67}$

Así, excluyendo posibles causas de la dulzura del beso, Patrizi lleva a Delfino a lo que parece resultar una verdad indudable: "Es por tanto el amor el que pone la dulzura en el beso, pues éste sin amor carece de dulzura, igual que la madera no arde ni calienta si no hay fuego". ${ }^{68}$ No es el beso en sí mismo el que despierta tan agradables sensaciones, pues si así fuese, las provocaría viniese de quien viniese. El beso es sólo el vehículo, el instrumento físico de transmisión de algo que no lo es. Y Patrizi llega a esta

\footnotetext{
64 Patrizi (1975: 136).

${ }^{65}$ Bembo (2000: 3, XI-XXIII, en pp. 153-177).

${ }^{66}$ En realidad, ya otros autores habían aludido a los besos. Por ejemplo, Castiglione, en El cortesano, admite el intercambio de besos en la relación amorosa de tipo platónico, en cuanto que contribuye a la conexión de las almas de los amantes. También lo hace Flaminio Nobili, cercano al naturalismo de Patrizi y como él crítico con los neoplatónicos al estilo de Bembo, en su Trattato dell'Amore Humano (1567), en Nelson (1958: 143-147). Unos años más tarde lo hará Annibale Romei en sus Discorsi (1585), en cuyo primer discurso Patrizi es el interlocutor principal. Romei, retomando la línea de asuntos cortesanos de Castiglione, admite el beso en el amor cortesano, pero no en los amores más puros, es decir, el neoplatónico y el matrimonial. Véase (Nelson 1958: 80, 118, 157-162).

${ }^{67}$ Patrizi (1975: 138).

${ }^{68}$ Parizi (1975: 139).
} 
conclusión utilizando una analogía que no es en absoluto casual: el fuego, que como se irá viendo a lo largo del diálogo, es esencial en el proceso del enamoramiento.

A fin de intentar desentrañar el misterio de la dulzura del beso, Patrizi propone una clasificación de sus tipos basándose en dos cosas: las partes del cuerpo en la que se dan y las formas de besar. Las seis partes elegidas son la nariz, el pecho, el cuello, las mejillas, los ojos y la boca. Las cuatro formas de besar son con los labios cerrados, succionando los labios, mordiéndolos y, por último, el beso con lengua. Sin duda alguna, reconocen los dos contertulios, los más dulces son los que se dan en el cuello y en la boca. Hay algo además en estos últimos que los diferencian de los demás, y es que, excepto en el caso de que se den con los labios cerrados, al mismo tiempo que se dan, se reciben. Aún así, la charla prosigue con una serie de preguntas y respuestas acerca de quién recibe más placer, el que da el beso o el que lo recibe. ${ }^{69}$ Patrizi dice estar convencido de que es el que lo recibe, pero Delfino expresa sus dudas, pues a él le resultan tremendamente excitantes los besos con lengua y los de chupetón para quien los da. Tal comentario, en apariencia ligero e intrascendente, será en cambio crucial cuando, unas páginas más adelante, Patrizi comience a exponer su explicación del fenómeno amoroso en términos fisiológicos. Si el mayor placer pertenece a quien recibe el beso, es porque el amante se bebe los espíritus de la persona amada, siempre que estos sean de buena calidad.

Si para que los besos resulten dulces al recibirlos es absolutamente necesario que el amor intervenga, será menester, considera Patrizi, detenerse en la naturaleza de tal pasión. Rehuyendo la tan arraigada separación neoplatónica entre un amor carnal, profano, y un amor sacro, divino y elevado, Patrizi mantiene que para elevarse a la comprensión de la naturaleza del amor, incluso del más espiritual, es necesario partir de sus causas y manifestaciones carnales. Fisiología, metafísica y cosmología neoplatónica y hermética se unen en una explicación del amor según la cual el cuerpo es instrumento necesario de las pasiones. La de Patrizi es una concepción astrológica del amor, entendiendo obviamente por astrología una filosofía natural según la cual todos y cada uno de los elementos del universo están ligados por cadenas de causalidad. Los astros no son meros cuerpos de una materia etérea, sino uno de los primeros pasos del despliegue emanantista del ente supremo, de la divinidad, receptáculo primero de todas las Ideas. Criaturas que a su vez llevan consigo y trasladan al mundo las potencias y cualidades divinas. ${ }^{70}$

Semejanza y belleza, se lee en el diálogo, son las madres que hacen nacer el amor en los corazones. La semejanza puede ser exterior o interior, y ciertamente la primera no puede ser considerada causa del amor. Solo la semejanza interior lo es. ${ }^{71}$ A su vez, la semejanza interior puede ser de dos tipos: la que se refiere a las cualidades del alma y la que deriva de las cualidades del cuerpo. Para explicar la primera, la semejanza del alma, Patrizi recurre a ideas que ya había utilizado en La ciudad feliz y que intentaban dar respuesta a la difícil cuestión de la unión del alma con el cuerpo. Cuando Dios crea las inmateriales e incorpóreas (no dimensionales) almas, para que puedan iniciar su recorrido desde el empíreo hasta el centro del mundo, la Tierra, y allí unirse a los humanos cuerpos, se revisten de un sutilísimo "cuerpecillo etéreo". Con él, van descendiendo y atravesando en su viaje todas las esferas celestes e impregnándose de todas y cada una de las cualidades de los cuerpos junto a los cuales pasan. ${ }^{72}$ Cuando dos almas han realizado un recorrido similar, se han acercado a los mismos cuerpos celestes y han recibido sus influencias, tales almas serán por siempre semejantes. Son las disposiciones de los astros y su poder sobre las almas las que en última instancia permiten el parto del amor.

Antes de vestirse con el cuerpo etéreo y empezar su descenso hasta el mundo terrenal, el alma toma de Dios todas la Ideas, que son sus criaturas más bellas y excelsas, y entre ellas la idea de belleza. Así, cuando el alma llega por fin al vientre de las madres, guiándose por la idea del cuerpo que lleva consigo,

\footnotetext{
${ }^{69}$ Patrizi (1975: 140-144).

${ }^{70}$ Véase (Gómez: 2015).

${ }^{71}$ Patrizi (1975: 145-151). Ficino también había considerado la semejanza como causa de amor, relacionándolo con la idea de belleza espiritual, cfr. Ficino (1994: 41).

${ }^{72}$ Sobre este interesante concepto de "cuerpo etéreo", su historia, su uso por parte de Ficino y sus similitudes y diferencias con el concepto de "spiritus", véase Walker (1958) y (2000: 39-40). Véase también Granada (1984: 51-54). La idea ya se encontraba en Ficino (1576:13421345) y en el Della diversità dei furori poetici de Patrizi (1553: 46r-49v).
} 
da forma a la materia. Y dado que toda alma lleva consigo la idea de belleza, va plasmando, aunque salvando los impedimentos de la materia, las proporciones corporales, los lineamientos, los colores, las luces y las sombras del cuerpo. Las otras almas unidas a otros cuerpos, herederas también ellas de esa idea de belleza, son así capaces, aún sin ser conscientes de ello, de comparar la adecuación del nuevo ser a la perfecta idea de belleza. Cuando la comparación arroja excelentes resultados, se produce un placer estético que favorece el origen del enamoramiento. Sin embargo, avisa Patrizi, la belleza no basta para enamorar, pues es necesario distinguir afecciones del alma que a veces se confunden y nos hacen tomar por amor lo que no lo es. Una cosa es el gusto, otra bien diferente el deseo, y otra aún más diferente el amor. El gusto, dice el Chersino, es un gozo que experimenta el alma en sí misma al contemplar la belleza, mientras que el deseo es ese gusto sumado a la pulsión de proyectarse fuera de si mismo, de alcanzar lo otro. Cuando al gusto y al deseo se une la auténtica pasión, fuerza y voluntad por acceder a lo que gusta y se desea, es entonces, y solo entonces, cuando nace el amor. ${ }^{73}$

Todas estas elevadas disquisiciones siguen dejando a Delfino sin respuesta. Maravillosas explicaciones sobre la naturaleza del amor, reconoce. Pero el misterio de los besos y su capacidad para despertar en quien los da o los recibe semejante dulzura amorosa queda sin resolver. Es entonces, ya avanzada la conversación, cuando Patrizi desvela los mecanismos fisiológicos por los que se produce el enamoramiento. Semejanza y belleza, dice, son las madres primeras del amor, pero ¿cuál es el medio, el auriga, que de la belleza y la semejanza lleva el amor a los corazones? No hay duda: la luz y los rayos de los ojos. ${ }^{74}$ Como ya hemos visto, el protagonismo de la luz de los ojos en el enamoramiento no era nada especialmente nuevo. Lo interesante en la exposición de Patrizi es el detalle con que explica esta potencia de los rayos luminosos que parten de los ojos. Los aspectos más metafísicos dejan paso a una explicación del amor en términos casi exclusivamente fisiológicos. La tradición hipocrático-galénica se une a la filosofía neoplatónica de la luz, a su filosofía de la luz. Hacía así su aparición en la producción intelectual de Patrizi un tema que será central en su filosofía más madura, la expuesta en la Nova de Universis Philosophia. ${ }^{75}$

Los rayos luminosos, que son similares a la belleza, dice Patrizi, transportan los espíritus que proceden del corazón de una persona, salen por sus ojos y al penetrar por los ojos de otra persona, se introducen por ellos y se van dirigiendo hacia su corazón, incendiándolo cuando llegan a él. Los rayos luminosos son los aurigas de los espíritus del cuerpo:

PATR. Los ojos, que no son sino un pasaje por el que el amor desde lo bello y semejante se transporta hasta vuestra alma.

DEL. ¿Y de qué manera se transporta, oh espíritu amoroso?

PATR. Por los rayos y la luz de los ojos, que similares a toda la belleza y lo bello, llevan consigo los espíritus amorosos emanados del corazón. Y al encontrarse con nuestros ojos, penetrando por ellos hacen llegar hasta nuestro corazón la belleza de la que nacieron, encendiéndolo con sus llamas. Y estos son los auténticos dardos, saetas y flechas de Amor, con las cuales disparando e incendiando los corazones, produce en ellos llagas tan dulces y llamas tan ardientes que por mucha dulzura que después venga, no sanan ni cicatrizan. ${ }^{76}$

Una explicación como esta solo es comprensible si se acepta la premisa de que los ojos, tanto los de los hombres como los de los animales, son órganos que poseen luz en si mismos. Y efectivamente la poseen, dice Patrizi, porque así como cada cosa de la naturaleza ha heredado ciertas cualidades de la divinidad y de los astros junto a los cuales su forma ha pasado en su descenso hasta unirse con la materia, los ojos han heredado la luz de su padre el Sol. ${ }^{77}$ No es, subraya, una mera suposición, ni una invención suya, sino algo, dice, atestiguado tanto por la experiencia como por los testimonios de numerosos autores. Experiencias y testimonios que, si bien hoy nos resultan peregrinos y fantasiosos, estaban plenamente

\footnotetext{
73 Patrizi (1975: 148-149).

${ }^{74}$ Patrizi (1975: 151 y ss.).

${ }^{75}$ Véase Gómez (2013: 221-234).

${ }^{76}$ En esta cuestión sobre la luz de los ojos, Patrizi hace casi una paráfrasis de parte del cap. IV del De amore Ficino.

${ }^{77}$ Patrizi (1975:153).
} 
arraigados en la tradición literaria. ${ }^{78}$ Patrizi añade además un argumento profundamente naturalista derivado de su modelo de la fisiología del cuerpo. Si los ojos son claros, dice, se debe a la presencia en ellos de los espíritus del cuerpo. Lo demuestra el hecho de que el ojo del hombre vivo es mucho más claro que el del muerto, pues tiene muchos más espíritus. Y además observamos que cuando la pupila se dilata es mucho más reluciente que cuando por algún esfuerzo se contrae, pues entonces los espíritus, agotados por el esfuerzo, dejan de fluir en abundancia hacia los ojos. ${ }^{79}$

Siguiendo el modelo fisiológico aristotélico galénico, Patrizi explica cómo los espíritus vitales generados en el corazón, entidades materiales de una extrema sutilidad, al ser calentados por el calor natural del corazón, se van elevando hasta llegar a salir por todos los poros del cuerpo, incluidos los diminutos agujerillos que se encuentran en los ojos. ${ }^{80} \mathrm{Al}$ salir los espíritus por los ojos, se unen a la luz que hay en ellos y, como montados en los rayos luminosos, van al encuentro de otros ojos, los deslumbran y aumentan sus poros, haciendo que puedan penetrar por ellos y mezclarse con los espíritus de la persona a la cual la mirada va dirigida. Unidos los espíritus de ambas personas, juntos emprenden su camino hacia el corazón, y así al calor natural del corazón del receptor se une el calor de espíritu "forastero", inflamándose aún más. ${ }^{81}$ Patrizi insiste en que la suya es una explicación naturalista de la pasión amorosa al indicar a Delfino que "esto ciertamente no sucede por encantamiento o hechicería, sino por causa natural". Se entiende ahora que Patrizi hiciese referencia más arriba, para referirse al proceso de enamoramiento, a la analogía con la madera que solo arde si hay fuego que la prenda.

Sin embargo, siendo los espíritus sustancias muy sutiles, con el tiempo se van consumiendo y si no hubiese ningún proceso de regeneración, acabarían por agotarse. Así como en el hígado es necesaria la llegada del quilo procedente de los alimentos para que se puedan generar los espíritus naturales, en el corazón son necesarios esos espíritus procedentes del hígado unidos al aire que llega al ventrículo izquierdo procedente de los pulmones (el pneuma) y al calor natural del corazón para que puedan generarse los espíritus vitales. Si en el momento de la diástole el corazón se llena de aire procedente de los pulmones, el cual toman principalmente por la nariz y la boca, pero también por todos los poros de la piel que envuelve al cuerpo, al contraerse en el momento de sístole, en cambio, los espíritus vitales salen disparados por las arterias hasta salir por la nariz, la boca y el resto de los poros del cuerpo. Es el ritmo natural del cuerpo, gracias al cual se refresca el corazón y se renuevan los espíritus para mantener al hombre en vida. Mas si esta renovación de espíritus basta para mantener la vida, al corazón enamorado le hace falta algo más para seguir estándolo: un flujo extraordinario de espíritus, los espíritus del amado que hagan perdurar esa inflamación propia de la pasión amorosa. Al estar junto al amado o la amada, al recibir los rayos de sus ojos, al tocarlo o besarlo, el amante absorbe por todos sus poros las exhalaciones de los espíritus salidos de su corazón. Es así como el amor se restaura en el corazón. De hecho, prosigue Patrizi, los amantes sienten mayor placer cuanto mayores son las zonas de contacto entre sus cuerpos, pues uniendo más poros de la piel, dejan que por ellos transiten y se unan más espíritus. Tampoco se suele sentir gran placer si el cuerpo del amado está frio, porque en tal estado los poros están encogidos y casi cerrados, impidiendo la salida de los sutiles espíritus e impidiendo que el amante los pueda absorber. ${ }^{82}$

Patrizi ha ido llevando así a Delfino a la comprensión de su pregunta: ¿por qué el beso despierta tanta dulzura? Si el enamoramiento se produce por un tránsito de los espíritus de un cuerpo al otro, el beso es el acto que permite una mayor y más intensa transferencia de tales espíritus. Cada beso lo hace a su manera y en su justa medida, pues no es comparable el beso en la mano al que se da en el pecho o en la boca, y tampoco lo es el que se da con un leve roce de los labios al que se da succionando con toda la pasión posible la lengua o cualquier otra parte del cuerpo del amado. Desde luego, el beso que Patrizi

\footnotetext{
78 Patrizi (1975: 153-154).

${ }^{79}$ Patrizi (1975: 153).

${ }^{80}$ Patrizi (1975:155).

${ }^{81}$ Esta indicación sigue a una referencia a los versos de Petrarca en los cuales se relata cómo éste enfermó por la mirada de su amada Laura: “iQuién vio ventura tal, cuando de uno / del par de ojos que más bello yo auguro, /viéndolo de dolor malo y oscuro, / llegó luz que hizo el mío enfermo y bruno!” [Rime, CCXXXIII]. Fueron los rayos de los ojos de la enferma Laura, que portaban sus espíritus enfermos, los que transmitieron la enfermedad al pobre Petrarca.

${ }^{82}$ Patrizi (1975: 159-162).
} 
denomina "a succio", de chupetón, el que succiona la boca o la piel del amado, es el que más dulzura provoca porque con él se absorbe una gran cantidad de espíritus. Pero mejor aún si el beso es con lengua, pues al ser esta un cuerpo completamente esponjoso y lleno de poros, por ella penetran los espíritus mejor que por cualquier otra parte del cuerpo. El beso con lengua, además, hace que el amado pueda saborear los humores del amante, sintiendo con más intensidad y cercanía el cuerpo y el temperamento del amado.

Pero vayamos ahora a la cuestión del beso. La causa de que el beso al enamorado sea tan dulce es que gracias a él el amante atrae y bebe los espíritus del amado. Y tal cosa sucede tanto con los besos dados en la mano, en el pecho, el cuello, la mejilla, los ojos o la boca. Por la misma razón, el beso de chupetón, el que absorbe los labios del amado, es más dulce que el dado solo con el roce de los labios, pues no solo recoge los espíritus que su corazón ha expulsado, sino que con su fuerza absorbe y bebe una mayor cantidad. Es también por esto que el beso de chupetón es más dulce si se da en la boca que en otras partes del cuerpo, pues al ser mayor la entrada, se absorben por ella más espíritus que por los pequeños agujeritos de la piel. Más dulce aún que este beso de chupetón es el beso con lengua, pues con él no solo se absorbe la misma cantidad de espíritus que con el de chupetón, sino también los de la lengua, la cual es un cuerpo completamente esponjoso, completamente lleno de espíritus, y además saborea los humores interiores del cuerpo amado. ${ }^{83}$

Se quedará Delfino, al final del diálogo, con un misterio inconfesable: el del beso en el cuello, el cual despierta una pasión inusitada y cuya causa el espíritu amoroso que habla por boca de Patrizi prefiere mantener en secreto. Sí da, sin embargo, una pista: "se siente mucha mayor dulzura besando en la parte izquierda del cuello". ${ }^{84}$ Aunque no especifica más, está claro que es una referencia al modelo galénico del funcionamiento del cuerpo humano. Recordemos que en el hígado se generan los espíritus naturales, una parte de los cuales pasa, junto con la sangre, al ventrículo derecho del corazón a través de la vena cava. Ya en el corazón, una parte de esa sangre pasa por la vena arteriosa hasta llegar a los pulmones. Otra parte pasa al ventrículo izquierdo por los poros del supuesto septum, y es en este ventrículo izquierdo donde la sangre venosa, mezclándose con el aire procedente de los pulmones (el pneuma), se convierte en sangre arteriosa y se generan los espíritus vitales. El beso en la parte izquierda del cuello es, por tanto, el que puede absorber, por su cercanía al lugar donde se generan, la mayor cantidad de espíritus vitales procedentes del corazón y provocar mayor placer en el amante.

La concepción patrizina del amor sorprende por su radical naturalismo. Prácticamente ninguna de sus afirmaciones era de creación propia, sino fruto de una larga tradición de interpretación del amor en clave médica. La descripción que hace Patrizi en Il Delfino, sin embargo, destaca por su detalle. Y lo que llama más la atención: su platonismo es innovador y crítico con sus propias fuentes de inspiración. Si en la mayoría de los platónicos el amor carnal era denigrado, o por lo menos considerado un simple, aunque peligroso, paso hacia el amor divino, para Patrizi el amor carnal -como el resto de los actos naturales de hombres y animales- no es bueno ni malo. El amor "por su naturaleza misma no es cosa ni virtuosa ni viciosa, ni loable ni abominable, como no lo son el comer, el beber, el dormir o cualquiera de las otras actividades naturales", se lee en uno de los comentarios a las rimas de Contile (Rime, 44). También es cierto que si bien Il Delfino destaca por concentrarse en los procesos fisiológicos que generan y transmiten el amor carnal, Patrizi no lo separa totalmente del amor divino, pues considera que el ejercicio del amor humano, cuando el amante es virtuoso, conduce siempre al perfeccionamiento de la virtud, lo cual le lleva a "operar divinamente". El amor carnal, además, se parece a las actividades más elevadas del alma, las artes y la filosofía, en cuanto que, igual que a través de las producciones de estas últimas el hombre pretende dejar una huella eterna, así el amor tiende a hacer eterna su perfección procreando hijos. ${ }^{85}$

Il Delfino, como La ciudad feliz, nos muestra a un Patrizi que desde sus primeros años de formación tenía un proyecto de filosofía natural que iba más allá de su fascinación por el platonismo en sus aspectos

\footnotetext{
${ }^{83}$ Patrizi (1975: 161-162)

${ }^{84}$ Patrizi (1975: 163).

${ }^{85}$ Patrizi (1560: 48).
} 
metafísicos y morales. En ambos textos, su aspiración era explicar las causas naturales de las pasiones, políticas o amorosas. Los espíritus, esas mínimas y sutilísimas partes materiales que circulan por todo el cuerpo y todo el cosmos, no solo son las causas del mantenimiento de la vida, de la salud y la enfermedad del cuerpo, sino de todos los procesos que se dan en el mundo, incluidas las afinidades personales, las preferencias, los gustos, el amor o la organización jerárquica del estado. La unidad de todas las cosas, elemento fundamental de la visión neoplatónica del mundo, no puede excluir al hombre, a sus pasiones y a sus productos literarios o construcciones políticas. Esta naturalización corría el riesgo, por supuesto, de fagocitar la libertad del hombre, de atarlo completamente con las cadenas astrológicas de la causalidad natural. Era el peligro del que ya muchos habían alertado, pero que sobre todo Pico della Mirandola había convertido en elemento fundamental de su reflexión sobre la astrología y la magia natural. Aceptaba Pico, por supuesto, la existencia de unas cadenas astrológicas que determinan todos los fenómenos de la naturaleza. El hombre, sin embargo, ocupaba en ese cosmos natural un lugar privilegiado desde el que podía operar con los instrumentos de su conocimiento. El hombre está en el mundo, atado a la inmensa red de vínculos que unen todas las partes de universo, pero gracias a su conocimiento puede intervenir en ellos, escapando así del rígido determinismo astrológico al que están sujetos el resto de los seres a los que Dios no ha concedido el poder de conocer. La magia natural es precisamente esa capacidad de operar en la naturaleza y transformarla. Patrizi es plenamente consciente de los peligros de esa, digámoslo así, excesiva naturalización del hombre, un riesgo que intenta salvar sumando a su modelo fisiológico del amor la capacidad humana de conocerlo. El amor, recuerda Patrizi, no es encantamiento ni hechicería, sino pura naturaleza. Pero precisamente porque es naturaleza, si se conocen sus causas, sus efectos y sus síntomas, el hombre será capaz de aprovechar mejor las maravillas del enamoramiento, pero también de protegerse de sus frecuentes peligros: la enfermedad de amor, el hereos, que provoca "esas palpitaciones, languidecimientos y debilidad que a veces hacen enfermar, dejando a las personas inmóviles y sin sentido." Magia natural y fisiología del amor corren paralelas en la obra de Patrizi, pues así como el mago natural es capaz de modificar los efectos naturales conociendo sus causas, el conocedor de los procesos naturales del amor será también capaz de mantenerlo y evitar sus posibles efectos perniciosos.

\section{Referencias}

Abd Alghani, J. (2014). "Mediaeval Arabic Love Theory Between Dissonance and Consonance", Acta Orientalia Academiae Scientiarum Hungaricae. vol. 67. no. 3. 273-287.

Aguzzi Barbagli, D. (1972). "Un contributo di Francesco Patrizi da Cherso alle dottrine rinascimentali sull'amore". Yearbook of Italian Studies. vol. 2. 1-32.

Akasoy, A. - Giglioni, G. (2013). Renaissance Averroism and Its Aftermath: Arabic Philosophy in Early Modern Europe. Dordrecht. Springer.

Alvar, C. y Lucía, J. M. (eds.) (2008). Antología de la antigua lírica italiana. (De los primeros textos al Dolce Stil Novo). Madrid.

Arcari, P. M. (1935). Il pensiero politico di Francesco Patrizi da Cherso. Arti Grafiche Zamperini. Roma.

Avicena (1987). The Canon of Medicine of Ibn Sina. ed. de A. Sharafkandi. Soroush. vol 3. Teheran, Irán.

Beecher, D. - Ciavolella, Ma. (1990). A Treatise on Lovesickness. Jacques Ferrand. Syracuse University Press. Syracusa, Nueva York.

Bembo, P. (2000). Gli Asolani, ed. de C. Dionisotti. Turín. Einaudi. 
Bird, O. (1940). "The Canzone d'Amore of Cavalcanti According to the Commentary of Dino del Garbo. Text and Commentary”. Medieval Studies. II: 150-203.

Bird, O. (1941) "The Canzone d'Amore of Cavalcanti According to the Commentary of Dino del Garbo. Text and Commentary". Medieval Studies. III: 117-160.

Blanco Valdés, C. (2006). 'La teoría del 'buon perfetto' en Cavalcanti y Dante". Revista de Literatura Medieval. 19:113-128.

Bolzoni, L. (1980). L'universo dei poemi possibili. Studi su Francesco Patrizi da Cherso. Bulzoni. Roma.

Bolzoni, L. (1981). "L'Accademia Veneziana: splendore e decadenza di una utopia enciclopedica”, en Università, accademie e società scientífiche in Italia e in Germania nel Cinquecento. Annali dell'Istituto Storico Italo-Germanico. Il Mulino. Bologna.

Bolzoni, L. (1984). Il teatro della memoria. Studi su Giulio Camillo, Padua. Liviana.

Bolzoni, L. (2007). La estancia de la memoria. Modelos literarios e icononográficos en la época de la imprent. Siruela. Madrid.

Bolzoni, L. (2015). L'idea del theatro con «L'idea dell'eloquenza», il «De transmutatione» e altri testi inediti. Adelphi. Milán.

Burke, P. (1998). Le fortune del Cortigiano. Baldassarre Castiglione e i percorsi del Rinascimento europeo. Donzelli editore. Roma.

Capellán, A. (1990). De amore. Tratado sobre el amor, ed. de Inés Creixell Vidal-Quadras. El Festín de Esopo. Barcelona.

Castelli, P. (2002). Francesco Patrizi filosofo platonico nel crepuscolo del Rinascimento. Olschki. Florencia.

Castiglione, B. (2011). El cortesano. ed. de M. Pozzi. Cátedra. Madrid.

Cavalcanti, G. (2006). Rimas. edición de J. Aulicino y Amadeo Mandarino. Buenos Aires Poetry. Buenos Aires.

Chittick, William (2014). "Love in Islamic Thought Religion”. Religion Compass. 8/7. 229-238.

Ciavolella, M. (1976). La Malattia d'Amore dall'Antichita al Medioevo. Roma.

Cox, V. (1992). The Renaissance Dialogue: Literary Dialogue and its Social and Political Contexts. Castiglione to Galileo. Cambridge University Press. Cambridge.

Crespi, A. (1929). "La dottrina d'amore nell'Acerba di Cecco d'Ascoli". Giornale Storico della Letteratura Italiana. 93: 279-312.

Cull, J.- Dutton, B. (eds.). (1991). Un manual básico de medicina medieval. Bernardo Gordonio, Lilio de medicina. ed. crítica de la edición de 1495. Hispanic Seminary of Medieval Studies. Madison, Wisconsin.

Dadic, Z. (2000). Franciscus Patricius and His Natural Philosophical and Natural Scientific Thought. Skolska knjiga. Zagreb. 
Di Giulio, C. (1996). “La mimesi dell'amore nel'Cortegiano”. Romance Notes. vol. 36. n. 3. pp. $253-$ 260.

Dionisotti, C. (1966). "Bembo, Pietro". en Dizionario biografico degli italiani. vol. 8. 133-151. Istituto della Enciclopedia Italiana. Roma.

Fabian, S. B. (2014). Cecco vs. Dante: Correcting the Comedy with Applied Astrology. PhD. Columbia University.

Fackenheim, E. L. (1945). “A Treatise of Love by Ibn Sina”. Mediaeval Studies. vol. 7. 208-228.

Fellina, S. (2017). Alla scuola di Marsilio Ficino: Il pensiero filosofico di Francesco Cattani da Diacceto. Edizioni della Normale. Pisa.

Fenzi, E. (ed.) (1999). La canzone d'amore di Guido Cavalcanti e i suoi antichi commenti. Génova. Il Melangolo.

Ficino, M. (1576). Commentarium in Convivium Platonis. en Opera Omnia. Basilea T. II.

Ficino, M. (1994). De amore. Comentario a «El Banquete» de Platón. ed. de R. de la Villa. Tecnos. Madrid.

Ficino, M. (2005). Tres libros sobre la vida. ed. de Marciano Villanueva Salas. Asociación española de neuropsiquatría. Madrid.

Gagliano, M. - Guérin, P. - Zanni, R. (eds) (2016). Les deux Guidi Guinizzelli et Cavalcanti: Mourir d'aimer et autres ruptures. Presses Sorbonne Nouvelle. París.

Gentile, S. (1983). "In margine all'epistola «de divino furore» di Marsilio Ficino". Rinascimento. s. 2. XXIII (1983). 33-77.

Giffen, L. A. (1971). Theory of Profane Love Among the Arabs: The Development of the Genre. New York University Press. Nueva York.

Gómez, S. (2020). “Armonía del mundo y retórica celeste en la Venecia del s. XVI”. Éndoxa. 46, 357382.

Gómez, S., (2015). "Medicina y política en Francesco Patrizi: el cuerpo de La ciudad feliz". Asclepio. Revista de Historia de la Ciencia y de la Medicina. 61. 1, 2.

Gómez, S. (2013). "Telesio y el debate sobre la naturaleza de la luz en el Renacimiento italiano". en M. A. Granada (Ed.) Telesio y la nueva imagen del mundo en el Renacimiento italiano. Siruela. Madrid. 194-235.

Gónzalez Fernández, I. (2003). "Cavalcanti y Dante: distinta" filosofía y una "misma cuestión de amor". Actas del Congreso Internacional "La Lengua, la Academia, lo Popular, los Clásicos, los Contemporáneos". Vol. II. Alicante. Universidad de Alicante. 683-691.

Granada, M. Á. (1984). “Amor, spiritus, melancholia”. Faventia. vol. V. (6). 51-71.

Kristeller, P. O. (1963-67). Iter Italicum I. Londres.

Lacarra Lanz, E. (2015). "El «amor que dicen hereos» o aegritudo amoris", Cahiers d'études hispaniques médiévales. n. 38. 29-44. 
Leushuis, R. (2017). Speaking of Love: The Love Dialogue in Italian and French Literature. Leiden. Brill.

Lowes, J. L. (1914). “The Loverers Maladye of Hereos”. Medieval Philology. XI/4: 491-546.

Ludueña, F. (2019). "Voluptas Urania. Marsilio Ficino como exégeta neoplatónico y cristiano de la filosofía natural del amor en Guido Cavalcanti”. Praxis filosófica. 49: 61-86.

Maggi, A. (1999). "La bellezza e la speranza nel "Trattato dell'amore umano" di Flaminio Nobili (1568)”. Romance Notes. 39(3). 249-255.

Maier-Kaapoor, C. (2010). Marsilio Ficino's Medico-Philosophical Language of Love. Its Genesis and its Reception amongst Sixteenth-Century Italian Love Treatises. Baltimore. UMI Dissertation Services.

Martínez Sáez, N. (2015). "Andrés el Capellán ante el fenómeno del amor cortés en la Edad Media". Studium. Filosofía y Teología. 35. pp. 101-107.

McNamara, L. (2015). "Hippocratic and Non-Hippocratic Approaches to Lovesickness". en L. DeanJones y R. M. Rosen. Ancient Concepts of the Hippocrati. Leyden Brill. 308-327.

Moulton, F. (2015). "In Praise of Touch. Mario Equicola and the Nature of Love". The Senses and Society. 5:1. 119-130.

Muccillo, M. (1986). "Marsilio Ficino e Francesco Patrizi da Cherso". en G. C. Garfagnini (ed.). Marsilio Ficino e il ritorno di Platone. Olschki. Roma. 615-679.

Muratori, L. A. (1723-51). Rerum Italicarum Scriptores. Milán.

Musacchio, E. (1992). "The Role of the Senses in Mario Equicola's Philosophy of Love". en D. Beecher y M. Ciavolella (eds.). Eros and Anteros. The Medical Traditions of Love in the Renaissance. University of Toronto. Toronto. 87-102

Nelson, J. Ch. (1958). Renaissance Theory of Love. Columbia University Press.

Pagan, P. (1973-1974). "Sull'Accademia Veneziana o della Fama". Atti dell'Istituto veneto di scienze, lettere ed arti. CXXXII. 359-392.

Patrizi da Cherso, F. (1975). Lettere ed opuscoli inediti. ed. de D. Aguzi Barbagli. Istituto Palazzo Strozzi. Florencia.

Patrizi da Cherso, F. (1553). La città felice; Dialogo dell'honore, Il Barignano; Della diversità dei furori poetici; Lettura sopra il sonetto del Petrarca; La gola, e 'l sonno, e l'ociose piume. Venecia.

Patrizi, F. (1560). Le Rime di Messer Luca Contile divise in tre parti, con Discorsi et Argomenti di F. Patrizi. Venecia.

Pattini, D. (2002). Furor e ispirazione tra Medioevo e Rinascimento. PhD. Universidad Ca' Foscari de Venecia.

Plastina, S. (1992). Gli alumni di Crono. Mito, linguaggio e storia in Francesco Patrizi da Cherso. Messina. Rubbettino Editore.

Prins, J. (2015). Echoes of an Invisible World: Marsilio Ficino and Francesco Patrizi on Cosmic Order and Music Theory. Leyden: Brill. 
Puliafito, A. L. (1987). "Per uno studio della 'Nova de Universis Philosophia' di Francesco Patrizi da Cherso: note alla 'Panaugia'". Atti e memorie della Accademia toscana di scienze e lettere 'La Colombaria'. 52. 160-199.

Rivolta, A. (1933). Catalogo dei codici pinelliani dell’Ambrosiana. Milán. 58-60.

Rose, P. L. (1969). "The Accademia Venetiana. Science and Culture in Renaissance Venice". Studi Veneziani. XI. 191-242.

Stabile, G. (1974). “Giulio Camillo”. en Dizionario Biografico degli Italiani. Instituto della Enciclopedia Italiana. Roma. vol. XVII. 218-228.

Stone, G. B. (2020). Guido Cavalcanti: Poet of the Rational Animal. Nueva York. Routledge.

Tafuri, M. (1985). Venezia e il Rinascimento. Religione, scienza, architettura. Einaudi. Roma. 172-185.

Vasoli, C. (1989). Francesco Patrizi da Cherso. Bulzoni. Roma.

Vasoli, C. (2002). "L'Ermetismo a Venezia. Da Francesco Giorgio Veneto ad Agostino Steuco", en C. Gilly et al. Magia, alchimia, scienza dal' 400 al '700. Centro Di. Florencia. 31-67.

Wack, M. F. (1990). Lovesickness in the Middle Ages. The Viaticum and Its Commentaries. University of Pennsylvania Press. Philadelphia.

Walker, D. P. (1958). "The Astral Body in Renaissance Medicine". Journal of the Warburg and Courtauld Institutes. vol. 21. n. 1-2. 119-133.

Yates, F. (2005). El arte de la memoria. Siruela. Madrid.

Zonta, G. (1912). Trattatti d'Amore del Cinquecento. Laterza. Bari. 